\title{
Evaluation of the Effect of Remineralizing Agent on Bleached Enamel Surfaces Subjected to Erosion: An In Vitro Study
}

\author{
Manju Krishna EM ${ }^{1}$, Robin Theruvil ${ }^{2}$, Jain Mathew ${ }^{3}$, Saira George ${ }^{4}$, Midhun Paul $^{5}$, John Jacob ${ }^{6}$, Allu Baby $^{7}$
}

\begin{abstract}
Tooth bleaching helps to improve the appearance of discolored teeth. But the use of acidic food can lead to increased erosion after bleaching. Remineralizing treatment with a remineralizing agent is capable of reestablishing the lost enamel surface hardness after bleaching. In this study, changes in microhardness were analyzed upon the application of a remineralizing agent after subjecting the enamel surfaces to bleaching and erosive challenge.

Aim: The aim of this study is to evaluate the effect of a remineralizing agent on bleached enamel surfaces subjected to erosive challenge.

Materials used: (1) 35\% carbamide peroxide (Opalescence PF, Ultradent)—a bleaching agent; (2) Remin Pro-a remineralizing agent; (3) 1\% citric acid solution-an erosive agent.

Materials and methods: Samples were divided into three groups and subjected to bleaching and erosion treatment. Group I-treated with $35 \%$ carbamide peroxide then treated with $1 \%$ citric acid solution; group II — treated with $35 \%$ carbamide peroxide and a remineralizing agent followed by $1 \%$ citric acid solution; group III-without bleaching with $1 \%$ citric acid solution. The sample size calculated using the statistical package $G^{*}$ power (3.1.5) with a level of significance of 0.05 . The sample size obtained is $n=15,5$ samples per group. Gl, GIl, and GIII were subjected to the Vickers microhardness analysis. Loss of surface hardness loss (\% SHL) was analyzed.

Result: The lowest \% SHL is in group II-24.718 when compared with group I-35.048.

Conclusion: Post-bleaching application of a remineralizing agent helps to decrease the effect of erosion occurring as a consequence of bleaching. Keywords: Erosion, Remineralizing agent, Surface hardness loss, Tooth bleaching.

Conservative Dentistry and Endodontic Journal (2019): 10.5005/jp-journals-10048-0045
\end{abstract}

\section{INTRODUCTION}

Tooth bleaching is one of the most popular cosmetic dental treatments, which helps to improve the appearance of discolored teeth. Vital tooth bleaching is used for the removal of extrinsic stains caused by tea, coffee, and tobacco and for the reduction of intrinsic stains within the dentin. ${ }^{1}$ The process of tooth whitening lightens the color of a tooth. Whitening of teeth can be achieved by physical removal of the stain, or a chemical reaction. The chemical degradation of the chromogens within or on the tooth is termed as bleaching.

Hydrogen peroxide $\left(\mathrm{H}_{2} \mathrm{O}_{2}\right)$ is the active ingredient in the most commonly used whitening products and is delivered as either $\mathrm{H}_{2} \mathrm{O}_{2}$ or carbamide peroxide. ${ }^{2}$ Bleaching with carbamide peroxide is a well-accepted treatment modality for discolored teeth. ${ }^{3}$ Carbamide peroxide bleaching gels are more effective than $\mathrm{H}_{2} \mathrm{O}_{2}$ bleaching gels in treating teeth discoloration. ${ }^{4}$ But the indiscriminate use of bleaching agents causes a deleterious effect on hard and soft tissues of the oral cavity.

Increased intake of acidic food and beverages after bleaching can lead to increased erosion. Studies have proved that remineralization treatments with a remineralizing agent are capable of reestablishing lost enamel surface's hardness and alterations caused by dental bleaching. In the present study, changes in microhardness were analyzed upon the application of a remineralizing agent after subjecting the enamel surfaces to bleaching and erosive challenge.

\section{Materials and Methods}

The present in vitro study was approved by the Ethical Committee (SGDC/152/2017/1733/5). Ten freshly extracted human upper premolars were selected after confirming the absence of dental $\overline{{ }^{1-7} \text { Department of Conservative Dentistry and Endodontics, St. Gregorios }}$
Dental College, Kothamangalam, Kerala, India

Corresponding Author: Manju Krishna EM, Department of Conservative Dentistry and Endodontics, St. Gregorios Dental College, Kothamangalam, Kerala, India, Phone: +91 7907585854, e-mail: em. manju88@gmail.com

How to cite this article: Manju Krishna EM, Theruvil R, et al. Evaluation of the Effect of Remineralizing Agent on Bleached Enamel Surfaces Subjected to Erosion: An In Vitro Study. Cons Dent Endod J 2019;4(1):1-5. Source of support: St. Gregorios Dental College, NIT Calicut Conflict of interest: None

imperfections. Enamel blocks $(n=15)$ were obtained from these teeth and submitted to two phases of treatment: a bleaching phase and an erosive phase.

\section{Selection and Preparation of Enamel Blocks}

The crowns of healthy human premolars were fixed onto acrylic plates and sectioned at the level of cemento enamel junction (CEJ) and divided into two equal halves to obtain enamel specimens of $3 \times 3 \mathrm{~mm}$ dimension (Fig. 1) of 15 enamel samples, 5 samples per group. Finally, the samples were washed in running water and stored in a humid environment until they were submitted to the initial surface microhardness analysis.

\section{Assessment of Initial Surface Microhardness (Baseline)}

All the samples ( $n=15$ ) were submitted to an initial surface microhardness test. For this purpose, a microdurometer with a 


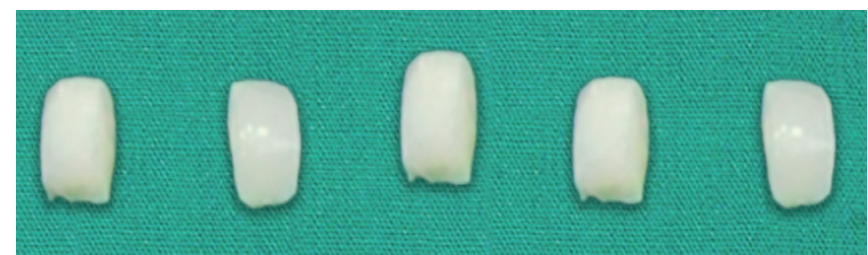

Fig. 1: Specimens of $3 \times 3 \mathrm{~mm}$ dimension

Vicker's type diamond penetrator (Fig. 2) was used (100 g load for 10 seconds). Two indentations spaced at a distance of $100 \mu \mathrm{m}$ from one another were made in the center of each sample, thus, obtaining the hardness values (Vickers hardness number [VHN]). The mean of these two values represented the hardness of the samples.

After obtaining the initial microhardness, the samples are randomly divided into three groups $(n=5)$ based on the concentration of a bleaching agent, the use of a remineralizing agent, and erosive treatment (Table 1).

\section{Bleaching Phase}

After prophylaxis with pumice and water in GI and GII, one drop of bleaching gel (35\% carbamide peroxide PF Opalescence, Ultradent) (Fig. 3) was deposited on the surface of samples for a period of 30 minutes according to the recommendation of the manufacturers (Fig. 4). After this period, all the samples were washed with distilled water for 5 minutes and stored in artificial saliva for 6 hours.

After bleaching treatment in Gll remineralizing agent Remin Pro (VOCO, Germany) (Fig. 5) were applied to the samples during a 15 day period for 5 minutes, twice daily (Fig. 6). Samples were then washed with distilled water and stored in artificial saliva.

\section{Erosive Phase}

The samples of the GI, GII, and GIII were immersed in a 1\% citric acid solution with pH 3.6 (Fig. 7), under agitation, for 5 minutes (Fig. 8).

Table 1: Samples were divided into three groups

\begin{tabular}{lll}
\hline & Bleaching phase & Erosive phase \\
\hline GI & $\begin{array}{l}\text { Treatment with 35\% } \\
\text { carbamide peroxide }(n=5)\end{array}$ & $\begin{array}{l}\text { Treatment with 1\% citric } \\
\text { acid solution }\end{array}$ \\
GII & $\begin{array}{l}\text { Treatment with 35\% } \\
\text { carbamide peroxide } \\
\text { followed by application of } \\
\text { remineralizing agent }(n=5)\end{array}$ & $\begin{array}{l}\text { Treatment with 1\% citric } \\
\text { acid solution }\end{array}$ \\
GIII & Without bleaching $(n=5)$ & $\begin{array}{l}\text { Treatment with 1\% citric } \\
\text { acid solution }\end{array}$ \\
\hline
\end{tabular}

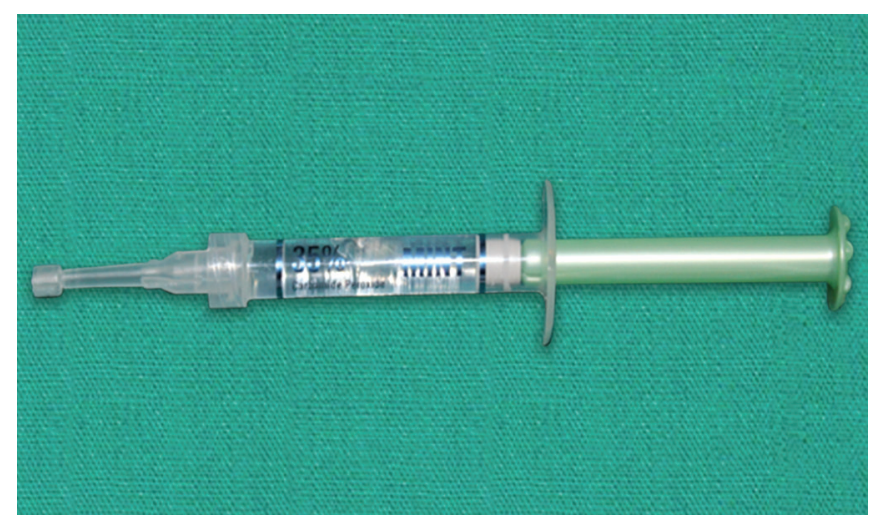

Fig. 3: Thirty-five percent carbamide peroxide PF Opalescence, Ultradent

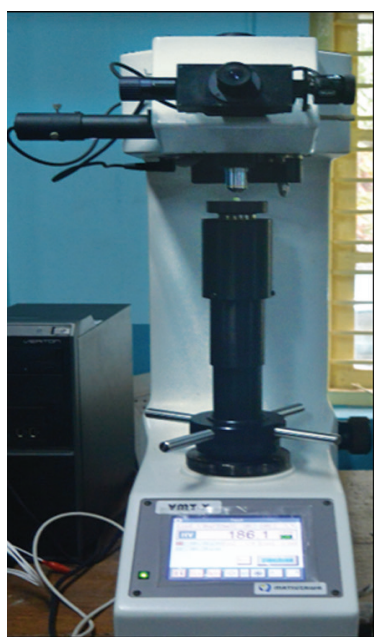

Fig. 2: Microdurometer with Vicker's type diamond penetrator

After this erosion protocol, they were stored in an artificial saliva solution for 120 minutes, which simulated the time of digestion. This sequence was performed twice a day for 3 consecutive days, totaling 30 minutes of exposure to the acid solution. The samples were kept in the artificial saliva solution for 12 hours after each erosive protocol.

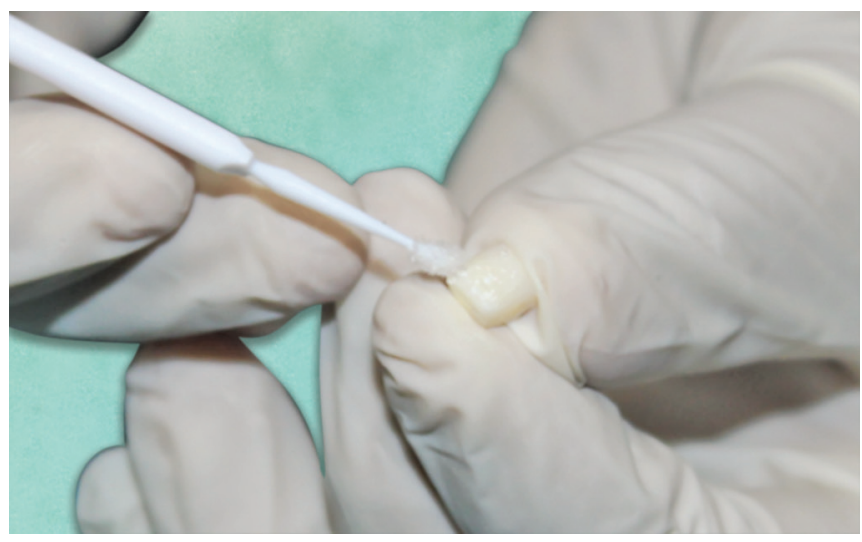

Fig. 4: Bleaching gel application

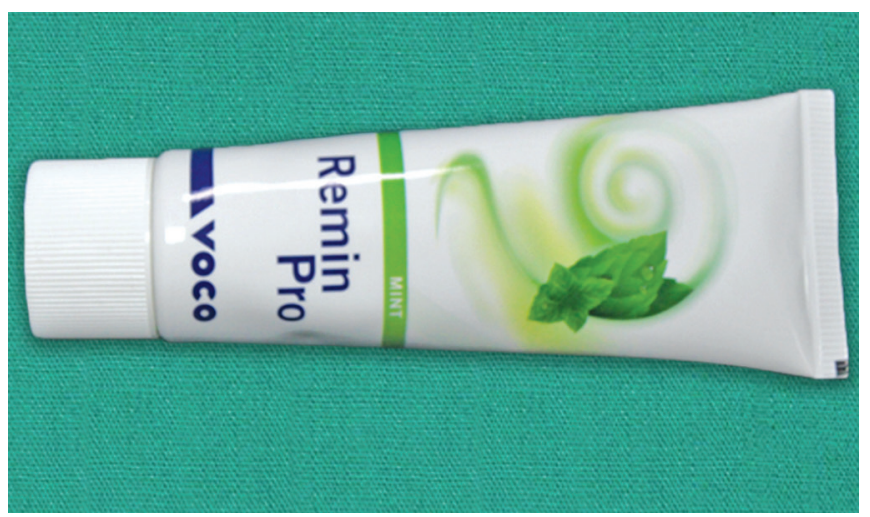

Fig. 5: Remin Pro (VOCO, Germany) 


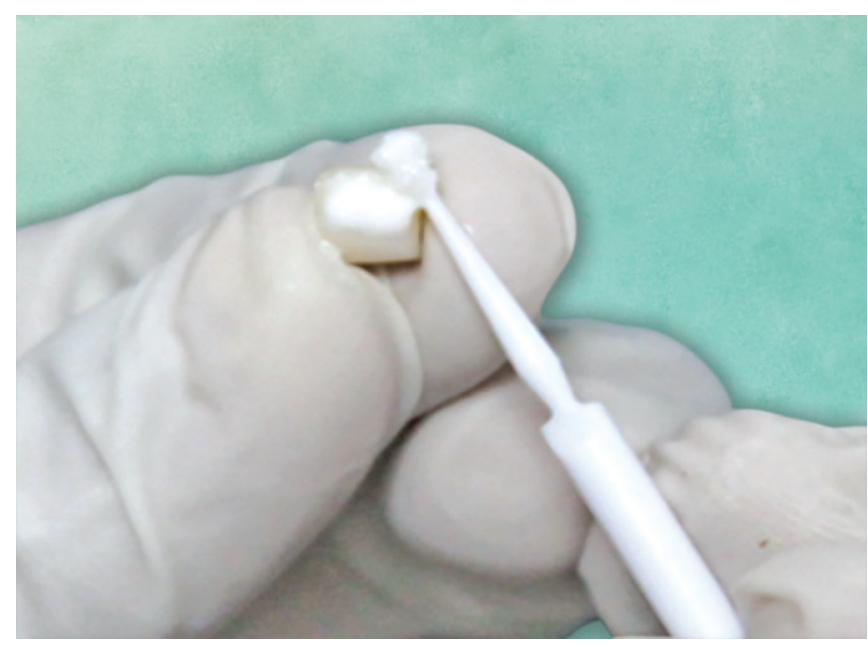

Fig. 6: Remineralizing agent application

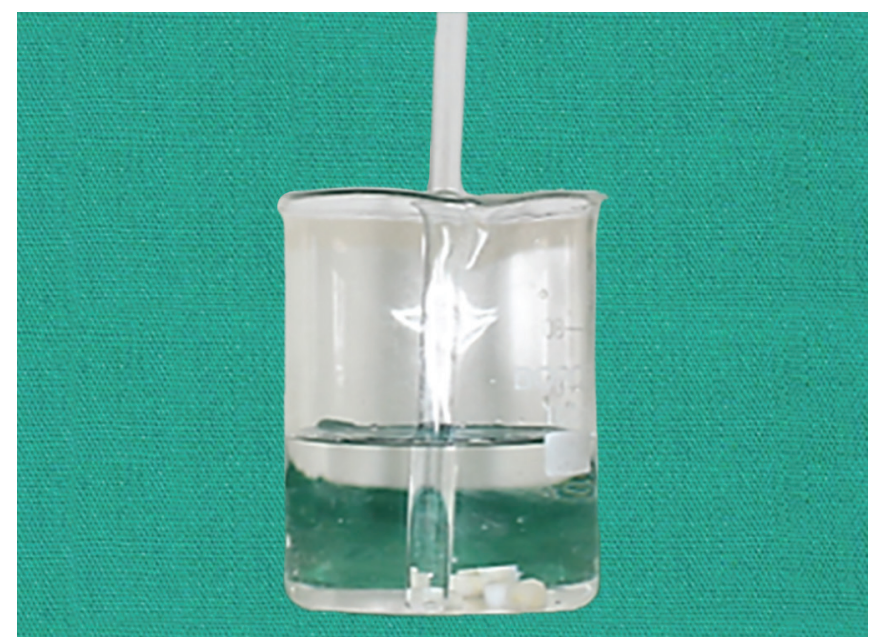

Fig. 8: Samples were immersed in a $1 \%$ citric acid solution

\section{Surface Microhardness Analysis After Erosive Phase}

The final microhardness was measured after two phases of treatment as the same pattern as that of the previous analyses. The percentages of surface hardness loss $(\% \mathrm{SHL})$ were obtained according to the following equation.

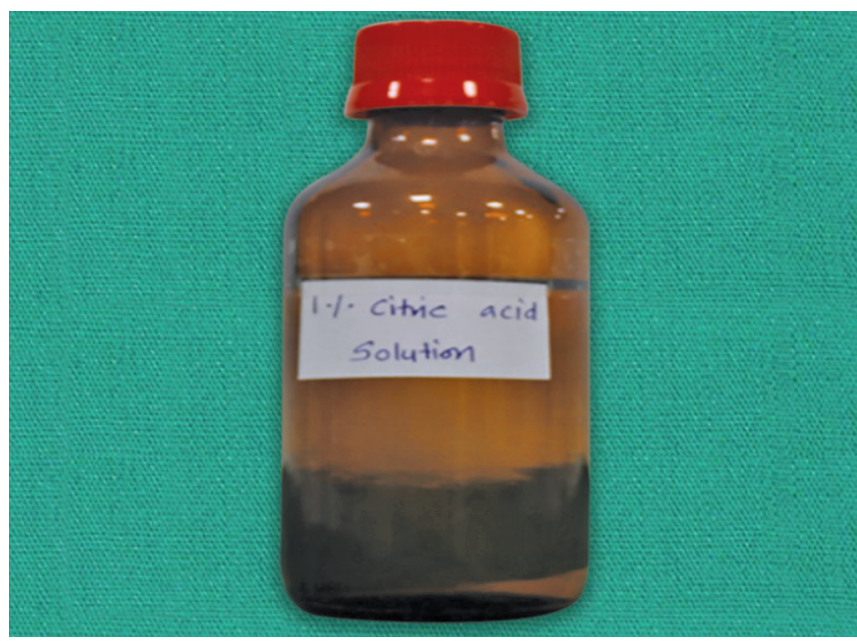

Fig. 7: One percent citric acid solution

$$
\% \mathrm{SHL}=\left(\frac{\text { Microhardness after erosion }- \text { Initial microhardness (baseline) }}{\text { Initial microhardness (baseline) }}\right) \times 100
$$

\section{Statistical Analysis}

One-way ANOVA is used for the analysis. The significance level is taken to be 0.05 . Statistical analysis was carried out using the statistical package, SPSS (version 22.0.0.0).

\section{Results}

Results of this in vitro study are given in Table 2 and are plotted graphically in Figure 9. After the samples were submitted to bleaching and erosive challenge, the \% SHL value was significantly higher in $\mathrm{Gl}$ in comparison with the other groups of treatment. However, Gll showed the lowest \% SHL after the erosive phase when compared with $\mathrm{Gl}$.

\section{Discussion}

The process of tooth whitening lightens the color of a tooth. The chemical degradation of the chromogens within or on the tooth is termed as bleaching. Vital tooth bleaching is used for the removal of extrinsic stains caused by tea, coffee, tobacco, and for the reduction of intrinsic stains within dentin. ${ }^{3}$

Table 2: Percentage of surface hardness loss value

\begin{tabular}{llrccc}
\hline & & $N$ & Mean & Std. deviation & Std. error \\
\hline Initial hardness & Group I & 5 & 182.380 & 8.762 & 3.918 \\
& Group II & 5 & 172.600 & 4.395 & 1.966 \\
& Group III & 5 & 169.600 & 6.383 & 2.855 \\
Hardness after erosion & Total & 15 & 174.860 & 8.426 & 2.176 \\
& Group I & 5 & 118.240 & 2.211 & 0.989 \\
& Group II & 5 & 130.000 & 7.036 & 3.147 \\
\% SHL & Group III & 5 & 139.880 & 6.273 & 2.805 \\
& Total & 15 & 129.373 & 10.517 & 2.716 \\
& Group I & 5 & 35.048 & 3.303 & 1.477 \\
& Group II & 5 & 24.718 & 2.301 & 1.029 \\
& Group III & 5 & 17.532 & 1.166 & 0.522 \\
\hline
\end{tabular}




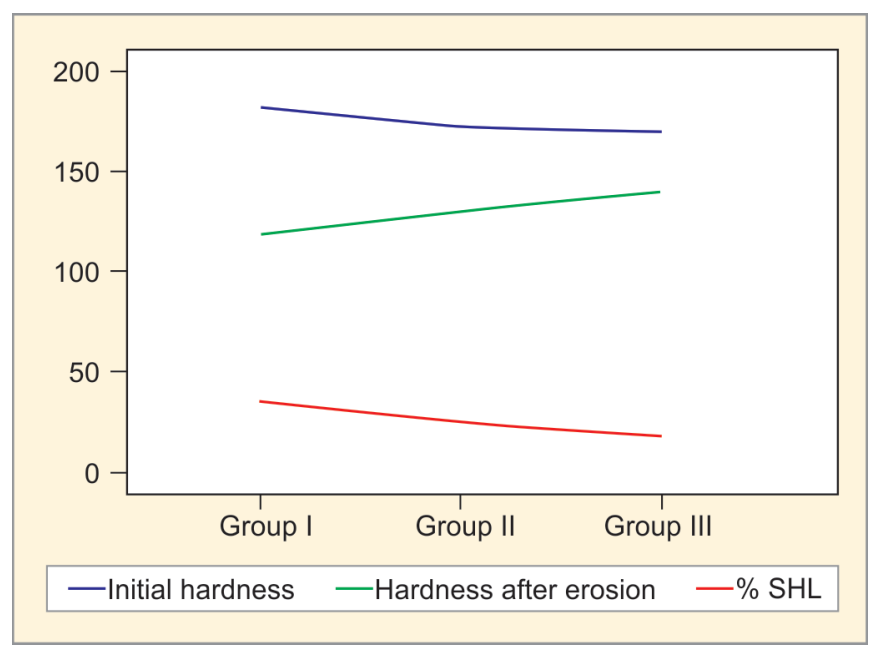

Fig. 9: Means plot shows that there is a gradual reduction in the loss of surface hardness from group I to group III

$\mathrm{H}_{2} \mathrm{O}_{2}$ is the active ingredient most commonly used in whitening products and is delivered as either $\mathrm{H}_{2} \mathrm{O}_{2}$ or carbamide peroxide. ${ }^{5}$ In essence, $\mathrm{H}_{2} \mathrm{O}_{2}$ is analogous to carbamide peroxide as it is ultimately released when the stable complex is in contact with water. This means that most tooth whitening is due to $\mathrm{H}_{2} \mathrm{O}_{2}$. When it diffuses into the tooth, $\mathrm{H}_{2} \mathrm{O}_{2}$ acts as an oxidizing agent that breaks down to produce unstable free radicals. In the spaces between the inorganic salts in tooth enamel, these unstable free radicals attach to organic pigmented molecules resulting in small, less heavily pigmented components. Reflecting less light, these smaller molecules create a "whitening effect."."

The bleaching gel typically contains between $10 \%$ and $44 \%$ carbamide peroxide, which is roughly equivalent to a 3-16\% $\mathrm{H}_{2} \mathrm{O}_{2}$ concentration. Carbamide peroxide of $35 \%$ resulted in a significant improvement in tooth color. ${ }^{6}$ A study published in the Journal of the American Dental Association showed that while carbamide peroxide appeared to produce slightly more dramatic results at first, ultimately products containing equivalent amounts of carbamide peroxide and $\mathrm{H}_{2} \mathrm{O}_{2}$ produced exactly the same results. ${ }^{7}$

In $35 \%$ carbamide peroxide, the recommended daily wear time is 30 minutes. There is no noticeable difference in sensitivity, using a $\mathrm{H}_{2} \mathrm{O}_{2}$ or carbamide peroxide product. Products with carbamide peroxide have a slightly longer shelf life than those with $\mathrm{H}_{2} \mathrm{O}_{2}$, although when refrigerated, all peroxide products have an increased shelf life. ${ }^{8}$

Carbamide peroxide is commonly used for at-home bleaching using a tray-based technique and dissociates into $\mathrm{H}_{2} \mathrm{O}_{2}$ (approximately a third of its former concentration) and urea, which further breaks down into water and ammonia. ${ }^{9,10}$ This last reaction increases the $\mathrm{pH}$ of the solution, reducing the enamel demineralization, and the proteolytic activity of urea can improve the bleaching effectiveness. Reduced tooth sensitivity can be expected using carbamide peroxide since the lower concentration of $\mathrm{H}_{2} \mathrm{O}_{2}$ is available. Among the products available on the market, carbamide peroxide-based whiteners with concentrations as high as $35 \%$ have been indicated for at-home bleaching procedures. Theoretically, a 35\% carbamide peroxide bleaching agent has the same bleaching effect as another agent with approximately $12 \% \mathrm{H}_{2} \mathrm{O}_{2}$ that could be used in-office with reduced chair-time.. ${ }^{11}$
Tooth bleaching procedures such as conservative, effective, and cost-effective techniques have become very popular choices. However, like all other treatment modalities, they are associated with some side effects.

Bleaching agents have created microstructural changes on the enamel surface results in demineralization, degradation, and alteration on surface microhardness and roughness of sound enamel surface. ${ }^{12}$

Morphological changes have been observed in the enamel, with erosion, craters, and porosity being reported by various authors. ${ }^{13,14}$

A bleached tooth treated with remineralization agents has produced a positive effect on enamel morphology and microhardness recovery. Remin Pro (VOCO, Germany) remineralizing paste contains calcium, phosphate in the hydroxyapatite form along with fluoride, and xylitol. ${ }^{15}$ It promotes remineralization by filling porous areas, forming a protective film on the tooth surface and thereby impeding the adhesion of bacterial plaque.

In this study, a bleached tooth treated with a remineralizing agent resulted in the lowest percentage of surface hardness loss after erosion when compared to bleached tooth treated without application of a remineralizing agent. By the application of a remineralizing agent, we can reduce the effect of erosion occurring after bleaching.

\section{Conclusion}

Erosion which usually occurs as a consequence of bleaching can be minimized by the application of remineralizing agents after bleaching.

\section{Clinical Significance}

The microhardness values in all samples after bleaching showed a significant reduction when subjected to an erosive challenge. Hence, the use of acidic food and beverages must be brought down after bleaching and the same should be advised to the patient.

\section{References}

1. Pretty IA, Edgar WN, et al. The effect of bleaching on enamel susceptibility to acid erosion and demineralisation. Br Dent J 2005;198:285-290. DOI: 10.1038/sj.bdj.4812126.

2. de Fátima Carvalho Vasconcelos M, Fonseca-Gonçalves A, et al. An in vitro evaluation of human enamel surfaces subjected to erosive challenge after bleaching. J Esthet Restor Dent 2017;29:128-136. DOI: 10.1111/jerd.12277.

3. Carey CM. Tooth whitening: what we now know. J Evid Based Dent Pract 2014;14:70-76. DOI: 10.1016/j.jebdp.2014.02.006.

4. Abouassi T, Wolkewitz $\mathrm{M}$, et al. Effect of carbamide peroxide and hydrogen peroxide on enamel surface: an in vitro study. Clin Oral Investig 2011;15:673-680. DOI: 10.1007/s00784-010-0439-1.

5. Da Costa JB, McPharlin R, et al. Comparison of two at-home whitening products of similar peroxide concentration and different delivery methods. Oper Dent 2012;37:333-339. DOI: 10.2341/11-053-C.

6. Attia RM, Kamel MM. Changes in surface roughness of bleached enamel by using different remineralizing agents. Tanta Dent $J$ 2016;13:179-186.

7. Mandel L. Dental erosion due to wine consumption. J Am Dent Assoc 2005;136:71-75. DOI: 10.14219/jada.archive.2005.0029.

8. McCracken MS, Haywood VB. Demineralization effects of 10 percent carbamide peroxide. J Dent 1996;24:395-398.

9. Peixoto AC, Vaez SC, et al. High-concentration carbamide peroxide can reduce the sensitivity caused by in-office tooth bleaching: 
a single-blinded randomized controlled trial. J Appl Oral Sci 2018;26:e20170573. DOI: 10.1590/1678-7757-2017-0573.

10. Kihn PW. Vital tooth whitening. Dent Clin North Am 2007;51:319-331. DOI: 10.1016/j.cden.2006.12.001.

11. Mokhlis GR, Matis BA, et al. A clinical evaluation of carbamide peroxide and hydrogen peroxide whitening agents during daytime use. J Am Dent Assoc 2000;131:1269-1277. DOI: 10.14219/jada.archive.2000.0380.

12. Pinto $C F$, Oliveira RD, et al. Peroxide bleaching agent effects on enamel surface microhardness, roughness and morphology. Braz Oral Res 2004;18:306-311.
13. da Silva Marques DN, Silveira JM, et al. Kinetic release of hydrogen peroxide from different whitening products. Eur J Esthet Dent 2012 Autumn;7(3):344-352.

14. Josey AL, Meyers IA, et al. The effect of a vital bleaching technique on enamel surface morphology and the bonding of composite resin to enamel. J Oral Rehabil 1996;23:244-250. DOI: 10.1111/ joor.12487.

15. Heshmat H, Ganjkar MH, et al. The effect of remin pro and MI paste plus on bleached enamel surface roughness. J Dent (Tehran) 2014;11:131-136. 